\title{
TAURINE ATTENUATES HEPATIC AND CARDIAC DAMAGE AND APOPTOSIS IN RABBITS FED A HIGH-FAT DIET
}

\author{
Gamal Hasan Abdel-Rahman \\ Department of Biology, Faculty of Science, Taif University, Taif, Kingdom of Saudi Arabia and \\ Department of Zoology, Faculty of Science, Assiut University, Assiut, Egypt
}

Received 2013-11-22; Revised 2013-11-30; Accepted 2013-12-28

\begin{abstract}
A hypercholesterolemia diet has been associated with the hepatic and cardiac abnormalities and the pathological changes. The present work was designed to investigate the histological and immunohistochemical changes in the liver and heart of rabbits when fed high fat diet and the possible protective role of an antioxidant "taurine". Twenty-four male white New Zealand rabbits were divided into four groups, 6 rabbits each. Group 1, served as a control, rabbits fed with a normal diet. Group 2, (taurine group), rabbits were given orally taurine $\left(10 \mathrm{mg} \mathrm{Kg}^{-1}\right.$ b.w/day) for 8 weeks. Group 3 (hypercholesterolemic group), rabbits fed ( $2 \%$ cholesterol-enriched diet for 8 weeks. Group 4 , rabbits fed $2 \%$ cholesterol-enriched diet plus taurine $\left(10 \mathrm{mg} \mathrm{Kg}^{-1}\right.$ b.w/day) orally for the same period. Histopathological examinations revealed that high cholesterol diet caused hepatic and myocardial tissue changes compared with rabbits fed with a normal diet. Including fatty degeneration, inflammations and necrosis of Hepatocytes and vacuolar degeneration, disorganization of myofibrils and necrosis of myocardial cells. Immunohistochemistry for caspase-3 for apoptosis were performed. Caspase-3 positive cells in the liver tissue and Caspase-3 positive area in myocardial tissue increased in high cholesterol diet group. Taurine markedly attenuate hypercholesterolemia-induced cardiac and hepatic histopathological changes in the cholesterol plus taurine group compared to the cholesterol group. Thus, the results suggest that taurine could play a beneficial role against hypercholesterolemiainduced complications in the liver and heart of the rabbits.
\end{abstract}

Keywords: Hypercholesterolemia, Taurine, Rabbit, Liver, Heart

\section{INTRODUCTION}

High-cholesterol dietary is known to play an important role in the induction of chronic diseases such as cardiovascular disease and hepatic abnormalities especially in developing countries (Vinaixa et al., 2010). Cardiovascular disease is the leading cause of morbidity and mortality mainly in many developing countries (O'Donnell and Nabel, 2011; Nabel and Braunwald, 2012). Total cholesterol and other lipids may have effects in the arterial tissues and myocardium (Toda et al., 2012). Reducing the intake of saturated fatty acids reduce the risk of heart disease, while polyunsaturated fatty acids elicit beneficial health effects (Cheema, 2012). Hypercholesterolemia has been found to induce oxidative stress in various organs such as the liver, heart and kidney ( $\mathrm{Du}$ et al., 2010). Hypercholesterolemia results in free radical production and thereby elevates lipid peroxides. Experimental hypercholesterolemia is associated with an increased production of reactive oxygen species and decreased activities of endogenous radical scavengers (Napol et al., 1999). Elevated blood concentration of cholesterol, especially in LDL, constitutes the primary risk factor for atherosclerosis and endothelial dysfunction (Bonetti et al., 2003). The progression of non-alcoholic fatty liver disease was Corresponding Author: Gamal Hasan Abdel-Rahman, Department of Biology, Faculty of Science, Taif University, Taif, KSA 
demonstrated in obese rats by feeding a highfat/cholesterol diet (Pan et al., 2006). Lipid peroxidation is the process by which unsaturated fatty acids are converted to free radicals via the abstraction of hydrogen (Young and McEneny, 2001). Due to the modern life, people could not successfully control their blood cholesterol, thus medication is considered option to decrease serious adverse effects, especially liver damage. Apoptosis is a process of programmed cell death in which defective and harmful cells are eliminated from a multicellular population (Wyllie, 1992). Recent studies stated that apoptosis is induced due to oxidative stress and oxidants (Chandra et al., 2000). Intensive efforts have been done to develop new natural and synthetic hypolipidemic and antihypercholesterolemic agents for controlling serum lipids, lipoproteins and atherosclerosis. It is reported that antioxidants attenuate the atherogenic process in animal models, mainly due to their free radical scavenging capabilities (Paul et al., 2001). Several studies indicated that cardioprotective diet can decrease sudden cardiac deaths, total cardiac deaths, non-fatal infractions (Singh et al., 2011). Taurine (2-aminoethane sulfonic acid), one of the most abundant free amino acids in many tissues, is well known to have several beneficial physiological actions, including antioxidation, detoxification, osmoregulation, cell membrane stabilization and neuromodulation (Wright et al., 1986; Huxtable, 1992). Several studies have demonstrated that dietary taurine showed a notable cholesterollowering effect in hypercholesterolemic rats fed a high cholesterol diet (Masuda and Horisaki, 1986; Murakami et al., 1999; Park and Lee, 1998; Hagar, 2004). It has been shown that taurine improves endothelial function and inhibits apoptosis of endothelial cell as well as decreases plasma level of LDL, which prevents initiation and progression of atherosclerosis (Fennessy et al., 2003; Murakami et al., 2002). Taurine exhibits antioxidative properties, membrane stabilizing effect, regulates intracellular $\mathrm{Ca} 2+$ concentration, inhibits apoptosis, reduces the levels of pro-inflammatory cytokines in various organs and controls blood pressure (Das et al., 2008; 2010; 2011; Manna et al., 2008; 2009). Additionally, the protective effects of taurine against cyclosporine-A-induced oxidative stress and hepatotoxicity have been documented previously (Hagar et al., 2006). Hsu et al. (2008) reported that taurine reduced hepatic apoptosis in NZB/W F1 mice.

Therefore, the present study aimed to investigate the protective role of taurine against liver and heart tissues of rabbits fed a hypercholesterolemic diet.

\section{MATERIALS AND METHODS}

\subsection{Animals}

Twenty-four male white New Zealand rabbits of about 1800-2000 g body weight, were kept in ventilated cages at the Animal House, Biology Department, Faculty of Science, Taif University. Animals were allowed 7 days for acclimatization at $24^{\circ} \mathrm{C}$ with $12 \mathrm{~h}$ light-dark cycle and fed standared laboratory diet and water $a d$ libitum before the experiment. Animal procedures were performed in accordance with Guidelines for Ethical behavior in the Care and Use of Animals.

\subsection{Experimental Design}

After one week of acclimation, animals were divided randomly into four groups (six rabbit for each group). Group1 (control group): Rabbits fed a standard diet. Group 2 (Taurine group): Rabbits were given orally taurine (10 mg Kg ${ }^{-1}$ b.w) daily by stomach tube for 8 weeks. Group 3: (hypercholesterolemic group): Rabbits fed ( $2 \%$ cholesterol enriched diet) for 8 weeks. Group 4 : Rabbits were fed $2 \%$ cholesterol-enriched diet plus taurine $\left(10 \mathrm{mg} \mathrm{Kg}^{-1}\right.$ b.w/day) orally for 8 weeks.

\subsection{Histological Evaluation}

\subsubsection{Light Microscopic Study}

At the end of the experimental period, rabbits were sacrificed by cervical dislocation and dissected. Small pieces from livers and hearts were removed immediately and fixed in $10 \%$ neutral buffered formalin, then dehydrated in ascending grades of alcohol, cleared and embedded in paraffin wax. Sectioned at 4-6 $\mu \mathrm{m}$ thick were cut and stained with Hematoxylin and Eosin (H and E) for general histological structure according to (Carleton et al., 1980). Monoclonal caspase-3 antibody immunostaining reactions were carried out using the avidin biotin peroxidase system (Sternberger, 1986).

\subsection{Immunostaining Procedure: (According to Sternberger, 1986)}

For the detection of caspase-3 protein, immunohistochemical staining was performed. Slides were deparaffinized, dehydrated, washed in phosphate buffer saline then covered with peroxide block staining and incubated at room temperature in humidity chamber for $10 \mathrm{~min}$. Monoclonal caspase-3 antibody was applied on the tissue sections then incubated horizontally in humidity chamber for an hour, at room temperature. After removal of excess buffer, the sections were 
incubated in preformed strept avidin peroxidase. DAB substrate-chromogen (3.3-Diaminobenzidine tetrahydrochloride) was applied on slides for 5-15 min until the desired brown color was obtained. Sections were counterstained Mayer's hematoxylin.

\subsection{Morphometry and Apoptotic Index}

Histological sections were studies by using a research microscope equipped with video camera and connected to a PC based image analysis system. Sigma
Scan Pro (version 4.0, Jendel Scientific, SPSS Inc., Chicago, USA) was used for image analysis and morphometrical data acquisition. For morphometrical study, sex slides from liver and heart of each group (6 sections per slide) were measured. Cell counts were performed using a magnification, 400 in different fields. Ten random fields were evaluated per slide. The immunostained active caspase- 3 cells of the liver were counted using a light microscope and calculated according to the following formula:

$$
\text { Apoptotic index }(\%)=\frac{\text { active caspase }-3 \text { immunopositive cells number }}{\text { total cells numberof the field }} \times 100(\text { Duan et al., 2003) }
$$

The immunostained active caspase- 3 areas of the heart were measured in ten random fields for each slide. The areas of caspase- 3 immunoactivity in the fields were bordered inside a measuring frame and the areas were masked by a different color to be measured.

\section{RESULTS}

\subsection{Histopathological Examination of the Liver}

The histological examination of rabbit liver sections revealed that control and taurine groups had a normal architecture with radially arranged hepatocytes around to centrilobular vein (Fig. 1A,B). In high cholesterol diet group, there were vacuolization, fatty degeneration in the hepatocytes, disintegration of hepatic cords. Hemorrhage and necrosis also were observed (Fig. 1C). In high cholesterol diet plus taurine group, there was less liver injury comparing to high cholesterol group. Fatty degenerations, cell vacuolization and necrosis were decreased in the hepatocytes (Fig. 1D).

\subsection{Immunohistochemistry and Image Analysis of the Liver}

The number of active caspase-3 positive cells (apoptotic cells) for each group were observed in the cytoplasm of liver cells. In control and Taurine treated animals, liver sections showed negative immune reaction to caspase-3 (no brownish punctuate in the cytoplasm, (Fig. 1E,F). Rabbits fed with highcholesterol diet demonstrated increased number of apoptotic cells (positive immune reaction to caspase3 ) than that of controls and taurine groups (Fig. 1G and Fig. 2). The number of cells expressing active caspase-3 was decreased in the high-cholesterol diet plus taurine group in comparison with highcholesterol diet group (Fig. 1H and Fig. 2).

\subsection{Histopathological Examination the Heart}

The histological examination of the heart of control and taurine groups showing that the myocardium are branching with anastomosing muscle fibers connected together by intercalated discs. The myocardial cells have oval centrally nuclei and homogeneous cytoplasm (Fig. 3A,B). Heart sections of a rabbits fed with high-cholesterol diet demonstrating vacuolar degeneration and disorganization of myofibrils and necrosis of myocardial cells. The nuclei appeared irregular in shape as well as separation and fragmentation of cardiac muscle bundles were observed (Fig. 3C). Heart sections of rabbits treated with high-cholesterol diet plus taurine showing amelioration of myocardial cell morphology. Most of the muscle fibers looked normal with normal nuclei and less disorganization of myofibrils (Fig. 3D).

\subsection{Immunohistochemistry and Image Analysis of the Heart}

In control and taurine treated animals, myocardial sections showed negative immune reaction to caspase-3 (Fig. 3D, E,F). High-cholesterol diet treated animals showed an increase in the mean area \% of caspase-3 immunoreacitivity (apoptosis) in the myocardium as compared with controls (Fig. 3G and Fig. 4). Myocardial sections of rabbits fed with high-cholesterol diet plus taurine, showed few areas $\%$ of positive immune reaction to caspase-3 (Fig. $3 \mathbf{H}$ and Fig. 4). 

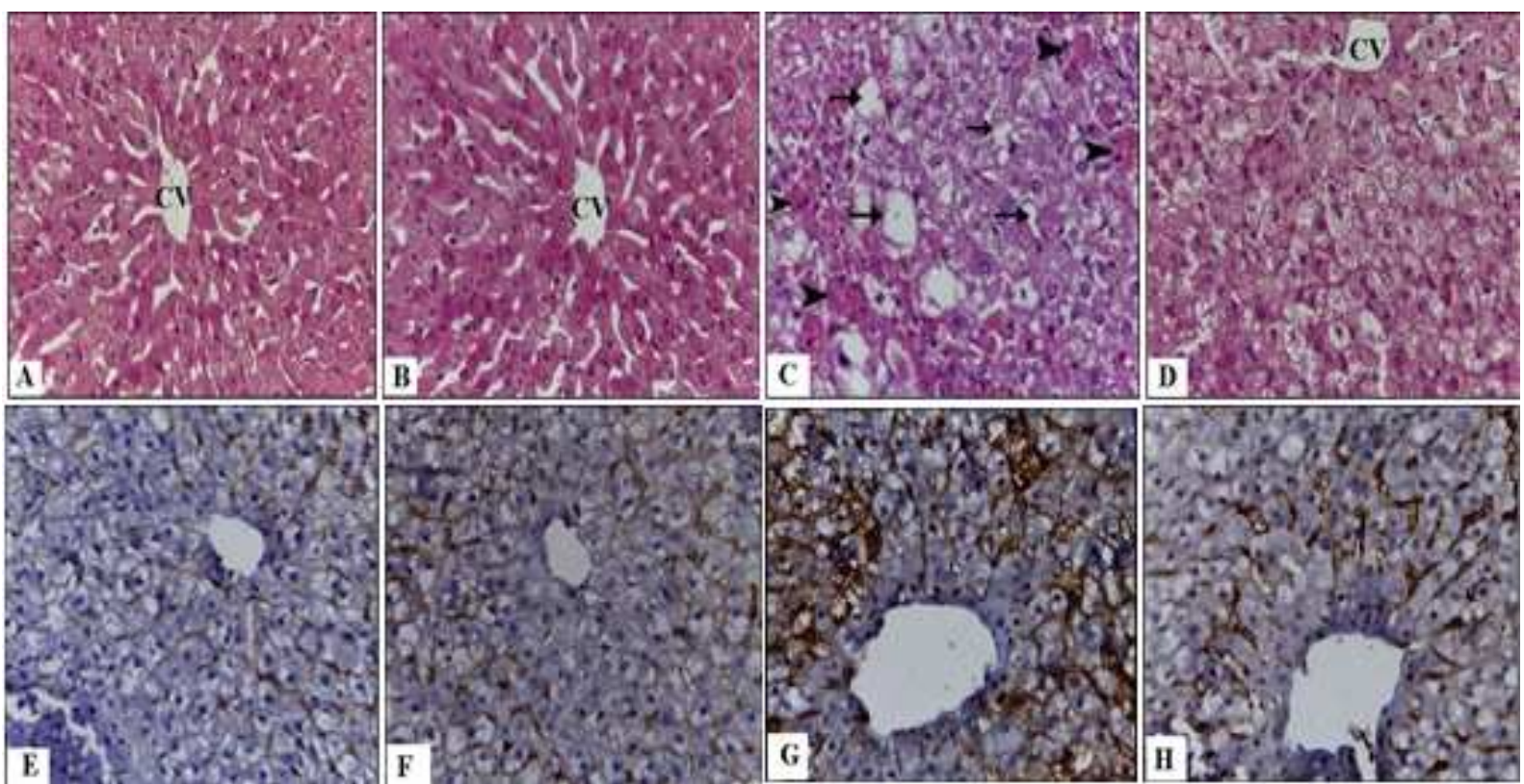

Fig. 1. A Photomicrograph of the liver sections stained with Hematoxylin and eosin (A-D). (A): Control rabbit showing normal hepatocytes around the central vien (CV). (B): Liver of rabbit treated with taurine showing normal hepatocytes architecture. (C): Liver section of rabbit fed with high-cholesterol diet demonstrating degeneration fat vacuoles (arrows), necrosis of hepatocytes and hemorrhage (arrow head. (D): Liver of a rabbit treated with cholesterol plus taurine showing less injury of central vein and less fat vacuole comparing to high cholesterol diet rabbits, ( $\mathrm{H}$ and $\mathrm{E}, \mathrm{X} 400)$.Immunolocalization of caspase3 in the liver of all groups (E-H). (E) Control and (F) taurine group showing no reaction; $(\mathrm{G})$ cholesterol group showing increased active caspase-3 immunopositive liver cells. $(\mathrm{H})$ : Cholesterol plus taurine group demonstrating a few immunopositive cells. (Caspase-3 Immunoreactivity, Counterstaining: Hematoxylin X, 400.

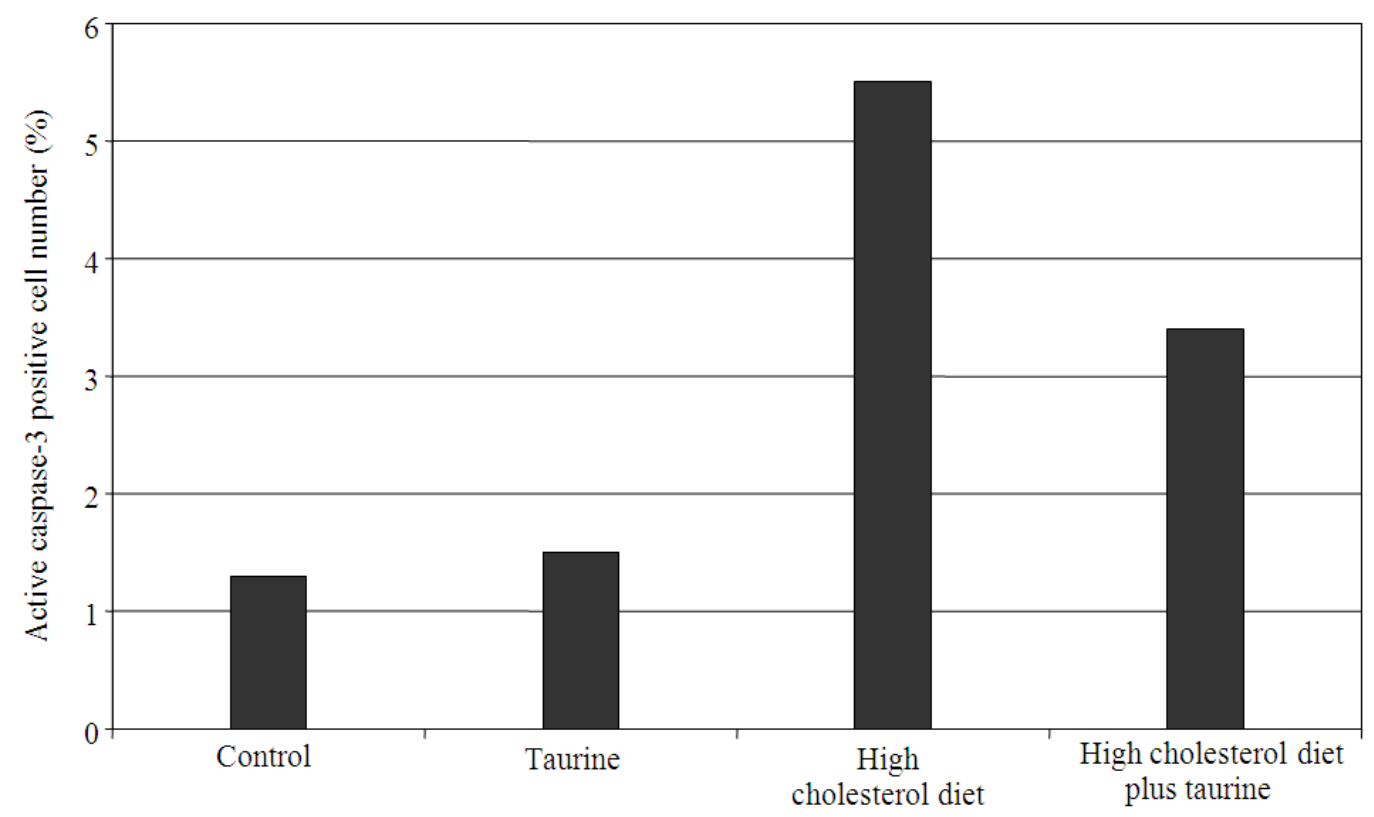

Fig. 2. The comparison of the active caspase-3 positive cell number (\%) in all groups 

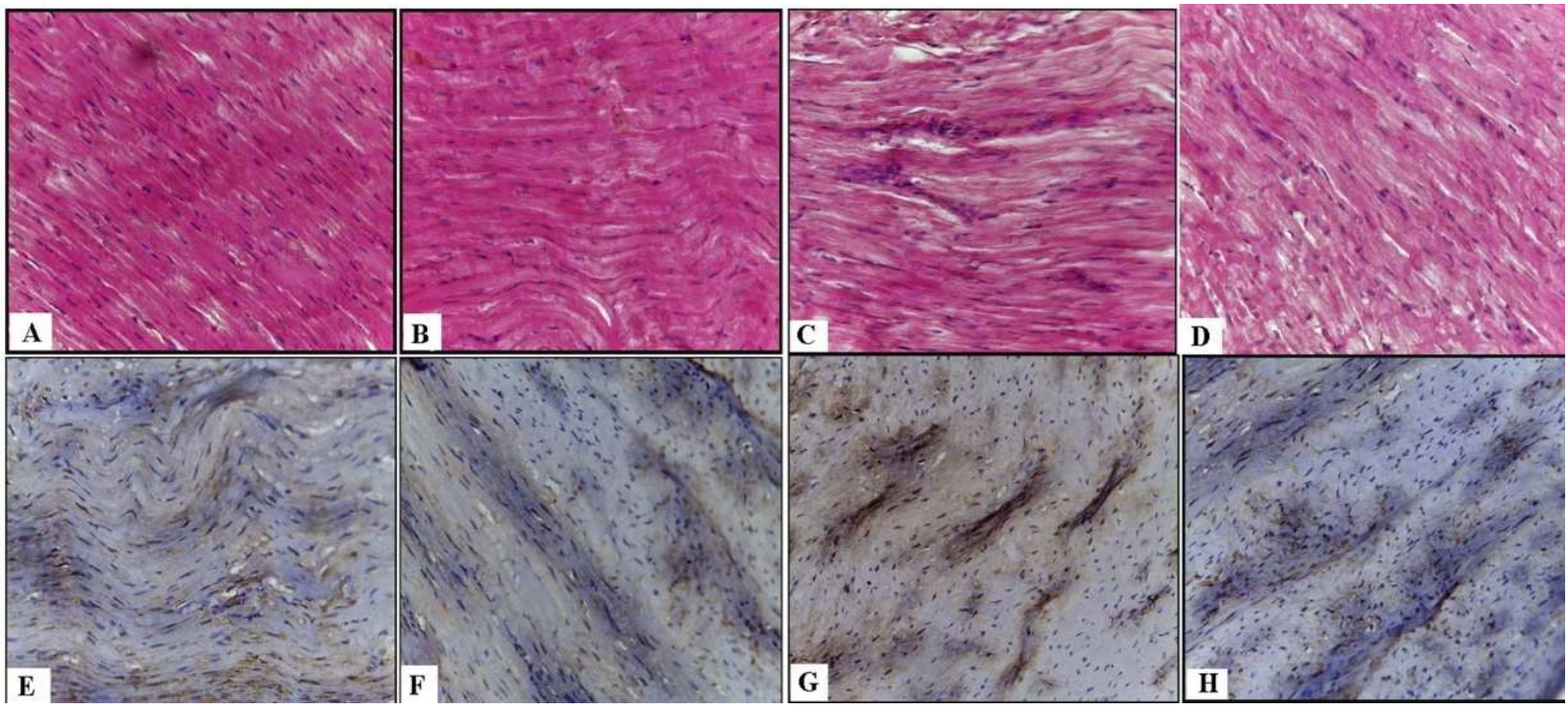

Fig. 3. A photomicrograph of a longitudinal section of the myocardium stained with Hematoxylin and eosin (A-D). (A): Control rabbit showing that myocardial cells are normal with centrally located oval nuclei and homogeneous cytoplasm. (B): Heart sections of rabbit treated with taurine demonstarating that heart section as seen in control. (C): Heart sections of a rabbit fed with high-cholesterol diet demonstrating histopathological changes including separation of cardiac muscle bundles, areas of myocytolysis, focal vacuolar degeneration and necrosis of myocardial cells. (E): Heart of a rabbit treated with cholesterol plus taurine showing better- preserved appearance of myocardial cell morphology (H and E, X 400). Immunolocalization of caspase-3 in the liver of all groups (E-H). (E): Control rabbit showing negative immune reaction to caspase-3. (F): Taurine group as a control one. $(\mathrm{G})$ : High-cholesterol diet group demonstrating areas of positive immune reaction to caspase-3. (H): High-cholesterol diet plus taurine group illustrating a few areas of immune reaction to caspase-3(Caspase-3 Immunoreactivity, Counterstaining: Hematoxylin X, 400)

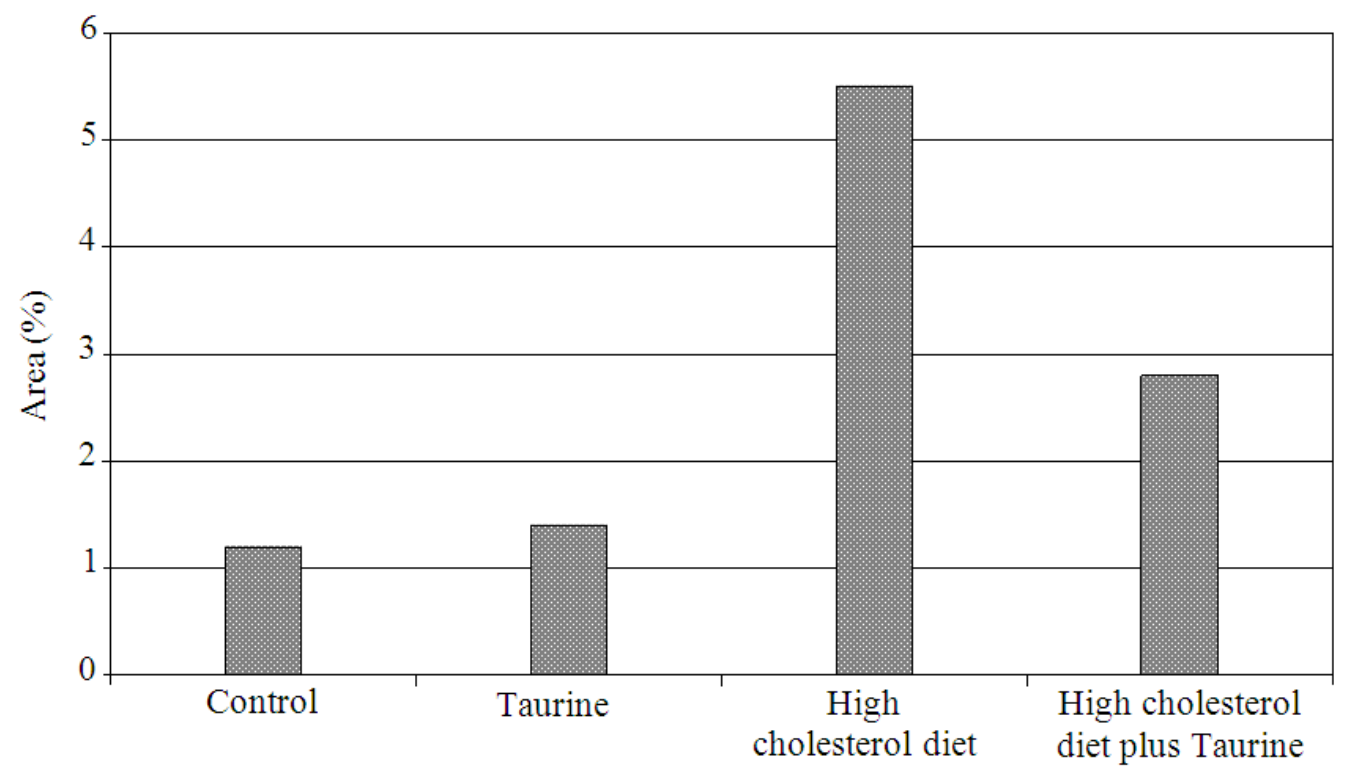

Fig. 4. Mean area $\%$ of caspase-3 immunoreactivity in the myocardium of different groups 


\section{DISCUSSION}

The consumption of high cholesterol diet leads to hypercholesterolemia for human and animals. Hypercholesterolemia induces oxidative stress and induce reactive oxygen species generation in different tissues such as liver, brain and kidney, which is known to cause damage of the cells (Park and Lee, 1998; Montilla et al., 2006; Prasad, 2008; Stapleton et al., 2010). The current study was designed to assess the possible protective role of taurine against hypercholesterolemia-induced hepatic and cardic changes by histological and immunohistochemical studies. Ingestion of high-fat diet may lead to fatty acid accumulation and hepatic cell damage and inflammation (Araya et al., 2004). High fat diet have effects on cell death and steatosis (Mei et al., 2011). Heart and liver are primary organs at risk from hypercholesterolemia. In hypercholesterolemic diets. The liver as the first organ to metabolize the ingested cholesterol and it is affected by oxidative stress that results from an imbalance between the production of free radicals and effectiveness of antioxidant defense systems (Lum and Roebuck, 2001). The present results revealed that rabbits fed high cholesterol diet leads to several abnormalities in liver sections such as degree of fat accumulation, inflammatory infiltration and necrosis of hepatocytes. This is in accordance with several studies which stated that high cholesterol diet causes hepatotoxicity and fatty liver (Hirako et al., 2011; Wang et al., 2011). Experimental hypercholesterolemia was found to induce damage of cardiovascular organs started earlier in the myocardium and clarified by disrupting of its structural pattern including degeneration of muscle fibers, cell death of cardiomyocytes and leukocytic infiltration (Caligiuri et al., 1999). The present results also showed that rabbits fed cholesterol-enriched diet produced heart injury and markedly pathological changes of cardiac muscle including vacuolar degeneration, loss of myofibrils and myocytolysis, necrosis of myocardial cells and separation of cardiac muscle bundles. Apoptosis, or programmed cell death, is a cellular process that important for many biological processes including tissue growth, embryonic development, response of tumors to cancer chemotherapy and the pathogenesis of neurodegenerative diseases. Apoptosis has been observed to play a role in a number of liver diseases such as Non-alcoholic steatohepatitis (Elmore, 2007). Caspases are a family of cysteine proteases that are present in the cytosol as inactive proenzymes
(Wyllie, 1992). They become activated when apoptosis is initiated and play an essential role in various stages of apoptosis. The present study indicated that hypercholesterolemia increased apoptotic hepatocyte numbers and myocardial cells apoptosis. These results are in agreed with Jiang et al. (2011) who demonstrated that the numbers of apoptotic cells increased in the rats that were fed a high-fat diet for 12 and 16 weeks. The present work, reported that hypercholesterolemi induces apoptosis in cardiomyocytes through the activation of caspase-3. This was in agreement with the previous findings of Wang et al. (2002) who reported that experimental hyperlipidemia induced by a high cholesterol diet (10\%) increased infarct size and apoptotic cell death. The present results confirmed this report and demonstrated that a moderate hypercholesterolemia ( $2 \%$ cholesterol diet for 8 weeks) also increased myocardial apoptosis. Several studies stated that inhibition of apoptosis by a variety of pharmacological and genetic approaches results in smaller infarction (Brocheriou et al., 2000; Mocanu et al., 2001) and improved cardiac function (Abbate et al., 2002; Chatterjee et al., 2003). Taurine, is known as to protect various disorders and has been demonstrated to have beneficial effects in nephropathy, cardiomyopathy and neuropathy, (Szymanski and Winiarska, 2008). Taurine is known to be beneficial on lipid metabolism and hepatic abnormality (Hagar, 2004). Histopathological observations in the present study revealed that the degree of high cholesterol diet-induced hepatic degeneration, inflammation, regeneration and necrosis were decreased in high cholesterol diet plus taurine treated group compared to high cholesterol diet group. Taurine also decreased apoptotic hepatocyte numbers and protects cardiac tissue against apoptosis induced by hypercholesterolemia. This beneficial effect of taurine may be directly related to its antioxidative effect, it possesses anti-inflammatory and cytoprotective properties which is in agreement with the previous findings (Das et al., 2010; 2011).

\section{CONCLUSION}

In conclusion, the results of the present study revealed that high cholesterol diet causes hepatic and cardiac damage as well as, apoptosis in the liver cells and cardiomyocytes of the rabbits. Co-administration of taurine protects hepatic and cardiac tissues against histopathological changes and apoptosis induced by hypercholesterolemia. 


\section{REFERENCES}

Abbate, A., G.G. Biondi-Zoccai and A. Baldi, 2002. Pathophysiologic role of myocardial apoptosis in post-infarction left ventricular remodeling. J. Cell Physiol., 193: 145-153. DOI: 10.1002/jcp.10174

Araya, J., R. Rodrigo, L.A. Videla, L. Thielemann and M. Orellana et al., 2004. Increase in long-chain polyunsaturated fatty acid n-6/n-3 ratio in relation to hepatic steatosis in patients with nonalcoholic fatty liver disease. Clin. Sci., 106: 635-643. DOI: $10.1042 / \mathrm{CS} 20030326$

Bonetti, P.O., L.O Lerman and A. Lerman, 2003. Endothelial dysfunction: A marker of atherosclerotic risk. Arteriosclerosis. Thromb. Vascular Biol., 23: 168-175. DOI: 10.1161/01.ATV.0000051384.43104.FC

Brocheriou, V., A.A. Hagege and A. Oubenaissa, 2000. Cardiac functional improvement by a human Bcl-2 transgene in a mouse model of ischemia/reperfusion injury. J. Gene. Med., 2: 326-333. DOI: 10.1002/1521-2254(200009/10)2:5<326::AIDJGM133>3.0.CO;2-1

Caligiuri, G., B. Levy, J. Pernow, P. Thoren and G.K. Hansson, 1999. Myocardial infarction mediated by endothelia receptor signaling in hypercholesterolemic mice. Proc. Nat. Acad. Sci. USA., 96: 6920-6924. DOI: 10.1073/pnas.96.12.6920

Carleton, H.M., R.A. Drury and E.A. Wallington, 1980. Carleton's Histological Technique. 5th Edn., Oxford University Press, ISBN-10: 0192613103, pp: 520.

Chandra, J., A. Samali and S. Orrenius, 2000. Triggering and modulation of apoptosis by oxidative stress. Free Radic. Biol. Med., 29: 323-332. DOI: 10.1016/S0891-5849(00)00302-6

Chatterjee, S., L.T. Bish and V. Jayasankar, 2003. Blocking the development of postischemic cardiomyopathy with viral gene transfer of the apoptosis repressor with caspase recruitment domain. J. Thorac. Cardiovasc Surg., 125: 14611469. DOI: $10.1016 / \mathrm{S} 0022-5223(02) 73229-7$

Cheema, S.K., 2012. Dietary fats and heart disease: From prenatal to postnatal environment. Am. Med. J., 3: 175-182. DOI: 10.3844/amjsp.2012.175.182

Das, J., J. Ghosh, P. Manna and P.C. Sil, 2008. Taurine provides antioxidant defense against $\mathrm{NaF}$-induced cytotoxicity in murine hepatocytes. Pathophysiology, 15: 181-190. DOI: $10.1016 /$ j.pathophys.2008.06.002
Das, J., J. Ghosh, P. Manna and P.C. Sil, 2010. Acetaminophen induced acute liver failure via oxidative stress and JNK activation: Protective role of taurine by the suppression of cytochrome P450 2E1. Free Radic. Res., 44: 340-355. DOI: 10.3109/10715760903513017

Das, J., J. Ghosh, P. Manna and P.C. Sil, 2011. Taurine suppresses doxorubicin-triggered oxidative stress and cardiac apoptosis in rat via up-regulation of PI3-K/Akt and inhibition of p53, p38-JNK. Biochem. Pharmacol., 81: 891-909. 10.1016/j.bcp.2011.01.008

Du, H., X. Zhao, J.S. You, J.Y. Park and S.H. Kim et al., 2010. Antioxidant and hepatic protective effects of lotus root hot supplementation in rats fed a high fat diet. J. Biomed. Sci., 17: S39-S39. DOI: 10.1186/1423-0127-17-S1-S39

Duan, W.R., D.S. Garner, S.D. Williams, C.L. FunckesShippy and I.S. Spath et al., 2003. Comparison of immunohistochemistry for activated caspase-3 and cleaved cytokeratin 18 with the TUNEL method for quantification of apoptosis in histological sections of PC-3 subcutaneous xenografts. J. Pathol., 199: 221228. PMID: 12533835

Elmore, S., 2007. Apoptosis: A review of programmed cell death. Toxicol. Pathol., 35: 495-516. DOI: 10.1080/01926230701320337

Fennessy, F.M., D.S. Moneley, J.H. Wang, C.J. Kelly and D.J. Bouchier-Hayes, 2003. Taurine and vitamin $\mathrm{C}$ modify monocyte and endothelial dysfunction in young smoker. Circulation, 107: 410-415.

DOI: 10.1161/01.CIR.0000046447.72402.47

Hagar, H.H., 2004. The protective effect of taurine against cyclosporine-A induced oxidative stress and hepatotoxicity in rats. Toxicol. Lett., 151: 335-343. DOI: 10.1016/j.toxlet.2004.03.002

Hagar, H.H., E. EI Etter and M. Arafa, 2006. Taurine attenuates hypertension and renal dysfunction induced by cyclosporine $\mathrm{A}$ in rats. Clin. Exp. Pharmacol. Physiol., 33: 189-196. DOI: 10.1111/j.1440-1681.2006.04345.x

Hirako, S., H.J. Kim, S. Shimizu, H. Chiba and A. Matsumoto, 2011. Low dose fish oil consumption prevents hepatic lipid accumulation in high cholesterol diet fed mice. J. Agric. Food Chem., 59: 13353-13359. DOI: 10.1021/jf203761t 
Hsu, T.C., S.Y. Chiang, J.H. Wu, C.C. Tsai and C.Y. Huang et al., 2008. Treatment with taurine attenuates hepatic apoptosis in NZB/W F1 mice fed with a high-cholesterol diet. J. Agric. Food Chem., 56: 9685-9691. DOI: 10.1021/jf8020255

Huxtable, R.J., 1992. Physiological actions of taurine. Physiol. Rev., 72: 101-163. PMID: 1731369

Jiang, Y., M. Zhao, W. An, 2011. Increased hepatic apoptosis in high-fat diet-induced NASH in rats may be associated with downregulation of hepatic stimulator substance. J. Mol. Med., 89: 1207-1217. DOI: 10.1007/s00109-011-0790-y

Lum, H. and K.A. Roebuck, 2001. Oxidant stress and endothelial cell dysfunction. Am. J. Physiol. Cell Physiol., 280: 719-741. PMID: 11245588

Manna, P., M. Sinha and P.C. Sil, 2008. Amelioration of cadmium-induced cardiac impairment by taurine. Chem. Biol. Interact., 174: 88-97. DOI: 10.1016/j.cbi.2008.05.005

Manna, P., M. Sinha and P.C. Sil, 2009. Taurine plays a beneficial role against cadmiuminduced oxidative renal dysfunction. Amino Acids, 36: 417-428. DOI: 10.1007/s00726-008-0094-x

Masuda, M. and K. Horisaki, 1986. Effect of taurine and homotaurine on bile acid metabolism in dietary hyperlipidemic rats. J. Pharmacobiodynamic, 9: 934-940. DOI: 10.1248/bpb1978.9.934

Mei, S., H.M. Ni, S. Manley, A. Bockus and K.M. Kassel et al., 2011. Differential roles of unsaturated and saturated fatty acids on autophagy and apoptosis in hepatocytes. J. Pharmacol. Exp. Ther., 339: 487-498. DOI: 10.1124/jpet.111.184341

Mocanu, M.M., G.F. Baxter and D.M. Yellon, 2001. Caspase inhibition and limitation of myocardial infarct size: Protection against lethal reperfusion injury. Br. J. Pharmacol., 130: 197. DOI: 10.1038/sj.bjp.0703336

Montilla, P., I. Espejo, M. C. Munoz, I. Bujalance and J.R. Munoz-Castaneda et al., 2006. Protective effect of red wine on oxidative stress and antioxidant enzyme activities in the brain and kidney induced by feeding high cholesterol in rats. Clin. Nutr., 25: 146-153. DOI: 10.1016/j.clnu.2005.10.004

Murakami, S., Y. Kondo and K. Tomisawa, 1999. Improvement in cholesterol metabolism in mice given chronic treatment of taurine and fed a high-fat diet. Life Sci., 64: 83-91. DOI: 10.1016/S00243205(98)00536-0
Murakami, S., Y. Kondo, T. Sakurai, H. Kitajima and T. Nagate, 2002. Taurine suppresses development of atherosclerosis in Watanabe Heritable Hyperlipidemic (WHHL) rabbits. Atherosclerosis, 163: 79-87. DOI: 10.1016/S0021-9150(01)00764-X

Nabel, E.G. and E. Braunwald, 2012. A tale of coronary artery disease and myocardial infarction. N. Engl. J. Med., 366: 54-63. DOI: 10.1056/NEJMra1112570

Napol, C., J.L. Witztum, F. De Nigris, G. Palumbo and F.P. D'Armiento et al., 1999. Intracranial arteries of human fetuses are more resistant to hypercholesterolemia-induced fatty streak formation than extracranial arteries. Circulation, 99: 20032010. DOI: 10.1161/01.CIR.99.15.2003

O'Donnell, C.J. and E.G. Nabel, 2011. Genomics of cardiovascular disease. N. Engl. J. Med., 365: 20982109. DOI: 10.1056/NEJMra1 105239

Pan, M., Y. Song, L., Xu and H.Z. Gan, 2006. Melatonin ameliorates nonalcoholic fatty liver induced by high-fat diets in rats. J. Pineal Res., 41: 79-84. DOI: 10.1111/j.1600-079X.2006.00346.x

Park, T. and K. Lee, 1998. Dietary taurine supplementation reduces plasma and liver cholesterol and triglyceride levels in rats fed a highcholesterol or a cholesterol-free diet. Adv. Exp. Med. Biol., 3: 319-325. PMID: 9635047

Paul, A., L. Calleja, J. Joven, E. Vilella and N, Ferre et al., 2001. Supplementation with vitamin E and/or zinc does not attenuate atherosclerosis in a polipoprotein E-deficient mice fed a high fat, highcholesterol diet. Int. J. Vitam. Nutr. Res., 71: 45-52. DOI: 10.1024/0300-9831.71.1.45

Prasad, K., 2008. Regression of hypercholesterolemic atherosclerosis in rabbits by secoisolaricresinol diglucoside isolated from flaxseed. Atherosclerosis, 197: 34-42. DOI: 10.1016/j.atherosclerosis.2007.07.043

Singh, R.B., S. Dharwadkar, F. DeMeester, L. Juneja and D. Pella, 2011. Role of cardioprotective diet in acute coronary syndrome. Am. Med. J., 2: 98-103. DOI: 10.3844/amjsp.2011.98.103

Stapleton, P.A., A.G. Good Will, M.E. James, R.W. Brock and J.C. Frisbee, 2010. Hypercholesterolemia and microvascular dysfunction: Interventional strategies. J. Inflam., 7: 54-54. DOI: 10.1186/14769255-7-54

Sternberger, L.A., 1986. Immunocytochemistry. 3rd Edn., John Wiley Medical, New York, ISBN-10: 0471867217, pp: 524. 
Szymanski, K. and K. Winiarska, 2008. Taurine and its potential therapeutic application. Postepy Hig. Med. Dosw., 62: 75-86. PMID: 18305447

Toda, E., T. Toru, R.B. Singh, S.E. Alam and F.D. Meester et al., 2012. Paleolithic-style diet and coronary artery disease: The tissue is the issue? Am. Med. J., 3: 183-193. DOI: 10.3844/amjsp.2012.183.193

Vinaixa, M., M.A. Rodriguez, A. Rull, R. Beltran and C. Blade et al., 2010. Metabolomic assessment of the effect of dietary cholesterol in the progressive development of fatty liver disease. J. Prot. Res., 9: 2527-2538. DOI: $10.1021 / \mathrm{pr} 901203 \mathrm{w}$

Wang, T.D., W.J. Chen and S.S. Su, 2002. Increased cardiomyocyte apoptosis following ischemia and reperfusion in diet-induced hypercholesterolemia: Relation to $\mathrm{Bcl}-2$ and Bax proteins and caspase-3 activity. Lipids, 37: 385-394. DOI: 10.1007/s1145002-0906-2
Wang, X., J. Hasegawa, Y. Kitamura., Z. Wang and A. Matsud et al., 2011. Effects of hesperidin on the progression of hypercholesterolemia and fatty liver induced by high-cholesterol diet in rats. J. Pharmacol. Sci., 117: 129-138. DOI: 10.1254/jphs.11097FP

Wright, C.E., H.H. Tallan and Y.Y. Lin, 1986. Taurine: Biological update. Ann. Rev. Biochem., 55: 427453. DOI: 10.1146/annurev.bi.55.070186.002235

Wyllie, A.H., 1992. Apoptosis and the regulation of cell numbers in normal and neoplastic tissues: An overview. Cancer Metastasis Rev., 11: 95-103. DOI: 10.1007/BF00048057

Young, I.S. and J. McEneny, 2001. Lipoprotein oxidation and atherosclerosis. Biochem. Soc. Trans., 29: 358362. DOI: 10.1042/BST0290358 